\title{
Temperature adaptability of two clades of Aphelinus mali (Hymenoptera: Aphelinidae) in China
}

\author{
Min Su${ }^{1 \dagger}$, Xiumei $\operatorname{Tan}^{1 \dagger}$, Qinmin Yang ${ }^{2}$, Fanghao Wan ${ }^{1,3}$ and Hongxu Zhou ${ }^{1 *}$
}

\begin{abstract}
Aphelinus mali (Haldeman) (Hymenoptera: Aphelinidae) is an effective natural enemy used in China to control the woolly apple aphid (Eriosoma lanigerum [Hausmann]) (WAA). Population of A. mali in China falls into two distinct genetic clades (Shandong clades and Liaoning clades). In the present results, the developmental threshold temperature of the Shandong clade $\left(9.82 \pm 1.44^{\circ} \mathrm{C}\right)$ was lower than that of the Liaoning clade $\left(10.72 \pm 0.24^{\circ} \mathrm{C}\right)$, while the effective accumulated temperature of the Shandong clade needed for development from oviposition to adult eclosion (126.45 \pm 16.81 day-degree) was significantly higher than that of the Liaoning clade (107.99 \pm 3.44 day-degree). The supercooling and freezing points of the Liaoning clade $\left(-27.66^{\circ} \mathrm{C},-27.17^{\circ} \mathrm{C}\right)$ were significantly lower than those of the Shandong clade $\left(-26.04{ }^{\circ} \mathrm{C},-25.54^{\circ} \mathrm{C}\right)$.

Some other differences between the two clades as well were the content of fat, trehalose, and protein of overwintering larvae of the Liaoning clade $(60.8 \%, 7.57 \mu \mathrm{g} / \mathrm{one}$ insect, $10.11 \mu \mathrm{g} / \mathrm{one}$ insect) as these were significantly higher than those of the Shandong clade (45.5\%, $5.73 \mu \mathrm{g} / \mathrm{one}$ insect, $8.05 \mu \mathrm{g} / \mathrm{one}$ insect). The occurrence of the first adult emergence of the Shandong clade of A. mali was earlier in the year than that of the Liaoning clade, allowing this clade to better control WAA in early spring. Meanwhile, the developmental duration from oviposition to adult emergence of the Shandong clade was longer than that of the Liaoning clade, and the cold tolerance of one of these, the more northerly Liaoning clade, is greater than that of the other, the more southerly Shandong clade. All of these factors imply differences in the pest control ability of the two clades of A. mali in their respective regions.
\end{abstract}

Keywords: Eriosoma lanigerum, Effective accumulated temperature, Supercooling point, Cold tolerance

\section{Background}

Woolly apple aphid (WAA), Eriosoma lanigerum (Hausmann), is a worldwide pest of apple, Malus pumila Miller (Jaume et al. 2015), and a quarantine pest in China (Zhang and Luo 2002). Since this aphid, which is native to North America, was introduced into China in Shandong province (Weihai) in 1914, in Liaoning province (Dalian) in 1929 from Japan, and in Yunnan province (Kunming) in 1930 through apple trees from America, it has had a serious impact on fruit production and acceptance of fruit for export. Aphelinus mali (Haldeman), a key

\footnotetext{
*Correspondence: hxzhou@qau.edu.cn

${ }^{\dagger}$ Equal contributors

${ }^{1}$ College of Plant Health and Medicine, Key Lab of Integrated Crop Pest Management of Shandong Province, Qingdao Agricultural University, Qingdao 266109, China

Full list of author information is available at the end of the article
}

parasitoid of this pest, was introduced several times into China during the period between 1940 and 1960 from the former Soviet Union and Japan and plays an important role in controlling WAA in Chinese orchards (Long et al. 1960).

Previous studies have found $A$. mali to be the most important parasitoid of WAA, making it a logical target for biological control by conservation (Gontijo et al. 2012). A. mali has been shown to provide a good control of WAA throughout the growing season in China, with field parasitism rates (50-90\%) in apple orchards (Zhou et al. 2010).

However, in China, WAA continues to expand westward into new apple-growing regions (Lu et al. 2013). Woolly apple aphid was first found in Shanxi province in 1999 in one location (Linfen), but by 2007, it had spread across $360 \mathrm{~km}^{2}$, infesting $6 \%$ of the area apple 
orchards (Wang et al. 2011). In Shandong province, surveys from 2000 to 2002 found WAA in about 8000 ha of orchards in Rizhao, Shandong area, with $10-20 \%$ of apple trees infested, resulting in an annual loss of $5 \times 10^{6} \mathrm{~kg}$ of apples (Wang et al. 2011). In Jiangsu province, WAA was found in 2005 in 4333 ha (Chu et al. 2008). Since 2007, WAA has spread to Hebei province, where it has caused great damage to orchards in several regions (Qinhuangdao, Tangshan, and Shijiazhuang) (Wu et al. 2009).

In China, $A$. mali is comprised of two distinct genetic clades (Zhang et al. 2014; Zhou et al. 2014). We hypothesized that the expansion of WAA in recent years is related to differences in low-temperature adaptability between these clades. Earlier studies outside of China have found that low-temperature adaptability differs among geographic populations of A. mali (Mols and Boers 2001). For example, in the Annapolis River valley of Nova Scotia (Canada), the parasitoid population appears earlier in the year than a strain of $A$. mali found in the Netherlands, thus providing better control in Nova Scotia than Holland. By the time, the Dutch strain of $A$. mali becomes active and its population was grown to levels that make its control by A. mali difficult (Mols and Boers 2001). The Nova Scotian and the Dutch strains of $A$. mali also differ in their low-temperature threshold (8.6 and $9.4{ }^{\circ} \mathrm{C}$, Nova Scotia vs Holland, respectively) and their effective accumulated temperature requirements, which were lower for the Canadian strain than for the Dutch strain (123.5 and 136.4 day-degree, respectively) (Mols and Boers 2001).

The present study aimed to determine the differences in the cold tolerance of different clades of $A$. mali in China to improve our understanding of the mechanism of WAA outbreaks and to provide insights into how to better use A. mali to control this economically important pest.

\section{Materials and methods Target insects}

Woolly apple aphid was collected from Qingdao $\left(36^{\circ}\right.$ $20^{\prime} \mathrm{N}$ ) in Shandong province. A. mali used in this study was collected from 4 to 5 apple orchards in the two locations: (1) Shandong province (Qingdao $36^{\circ}$ $20^{\prime} \mathrm{N}, 120^{\circ} 12^{\prime} \mathrm{E}$ ) and (2) Hebei province (Qinhuangdao $119^{\circ} 20^{\prime} \mathrm{E}, 39^{\circ} 25^{\prime} \mathrm{N}$ ), which is $889 \mathrm{~km}$ apart, representing the Shandong and the Liaoning clades, respectively. To obtain parasitoids from the field, in May and June 2015, apple branches, infested with woolly apple aphids were collected. The black-colored aphids (indicating parasitization) were isolated, and parasitized aphids were held in $1.5-\mathrm{mL}$ centrifuge tubes until adult parasitoid's eclosion. A. mali and WAA were held at $25{ }^{\circ} \mathrm{C}, 70 \% \mathrm{RH}$, and a 16:8-h L:D photoperiod.

\section{Measurement of effective accumulated temperature and developmental threshold temperature}

Fifteen males and 15 females of $A$. mali from each clade were placed together with an excess of hosts (ca 200 aphids) in Petri dishes $(13.5 \mathrm{~cm}$ dia). The parasitoids were removed after $24 \mathrm{~h}$, and the exposed WAA allowed to develop under one of five temperatures $(18,20,23$, 25 , and $28{ }^{\circ} \mathrm{C}$ ), noting the day of adult parasitoid emergence from each parasitized aphid. This process was replicated five times for each temperature, with an average of $0.073 \pm 0.006, \quad 0.087 \pm 0.018, \quad 0.120 \pm 0.031,0.160 \pm$ 0.035 , and $0.173 \pm 0.024$ parasitism rates within each replicate for each clade, respectively. All groups of potentially parasitized aphids were held at 70\% RH and a 16:8-h L:D photoperiod and observed daily to record when aphids turned black and adult parasitoid eclosion began. Newly emerged adults of $A$. mali were held separately under the same environmental conditions provided with $10 \%$ honey water. The sex and date of death of $A$. mali individuals were determined as well as the number of Day-Degree (DD) for each stage of development. Longevity of adults of each clade at each temperature was also determined.

The effective accumulated temperature $(K)$ and the developmental threshold temperature $(C)$ were calculated according to $\mathrm{Ma}$ (2009)

$$
\begin{aligned}
& K=\frac{n \sum V T-\sum V \sum T}{n \sum V^{2}-\left(\sum V\right)^{2}} \\
& C=\frac{\sum V^{2} \sum T-\sum V \sum V T}{n \sum V^{2}-\left(\sum V\right)^{2}}
\end{aligned}
$$

where $n$ is the number of groups in every experiment, $T$ the constant temperature, and $V$ is the average development rate.

\section{Supercooling point and freezing temperature of overwintering parasitoid larvae}

Overwintering larvae of $A$. mali were obtained by dissecting parasitized (black) woolly apple aphids collected in Changli $\left(4 \sim 16{ }^{\circ} \mathrm{C}\right)$ for the Liaoning clade on October 26, 2015, and in Qingdao $\left(7 \sim 13{ }^{\circ} \mathrm{C}\right)$ for the Shandong clade on November 17, 2015, using an anatomical lens.

Supercooling point (SCP) and freezing point (FP) of $A$. mali larvae were measured using a SUN-V type intelligent instrument in combination with a $-80^{\circ} \mathrm{C}$ ultra-low temperature refrigerator. When the instrument was connected with the temperature probe, one larva was placed on the probe and then inserted into the $200-\mu \mathrm{L}$ gun head of transfer liquid gun (to avoid contact with the pipe wall). The gun head was tightly wrapped with absorbent cotton and placed in the testing box, where absorbent cotton prevented rapid changes in the cooling rate. The whole probe and associated device were then 
placed into an ultra-low temperature refrigerator, where software of the measuring instrument system of the supercooling point -V1.3 was used to record temperature each second. Once below freezing, the SCP was found by reference to a sudden rise of temperature as energy is released upon larval freezing. The peak of this rise in temperature is the freezing point. This process was repeated 30 times for each clade.

\section{Determination levels of selected cryoprotectants in overwintering larvae}

Overwintering larvae of $A$. mali were collected all from the same single site and date. Thirty black aphids were taken at each time, the larvae were dissected out, and each treatment was repeated five times.

Free-water and fat content in overwintering A. mali larvae The fresh weight (FW) of 30 overwintered larvae as a group was determined using a microbalance (Sartorius BSA224S-CW, Beijing Co., Ltd.), then larvae were dried together at $60{ }^{\circ} \mathrm{C}$ for $48 \mathrm{~h}$. The dry weight (DW) of the samples was then obtained using the same microbalance, and the water content of the individual sample determined as (DW - FW)/FW $\times 100$ (Folch et al. 1957).

After measuring the DW, the sample of 30 dried larvae was placed in a $1.5-\mathrm{ml}$ centrifuge tube and homogenized in $20 \mu \mathrm{L}$ of a chloroform mixture $(2: 1)$ then $0.6 \mathrm{ml}$ of the chloroform and methanol mixture was added. The sample was then centrifuged at $2600 \mathrm{rpm}$ for $10 \mathrm{~min}$, and this process was repeated three times, each time removing the resulting supernatant. The residue was then baked at $60{ }^{\circ} \mathrm{C}$ in an oven for $72 \mathrm{~h}$ to determine the lean dry weight (LDW). The fat content of the insect was determined by the following formula: [(DW - LDW $) / D W] \times$ 100 (Folch et al. 1957).

\section{Trehalose and glycogen content in overwintering A. mali larvae}

Thirty overwintering larvae were added to $40 \mu \mathrm{L}$ of $10 \%$ trichloroacetic acid solution and homogenized by grinding. The material was then rinsed by $0.2 \mathrm{ml}$ of $10 \%$ trichloroacetic acid solution and centrifuged three times at $5000 \mathrm{rpm}$ for $10 \mathrm{~min}$. Between bouts of centrifugation, the precipitate was dissolved by $0.15 \mathrm{ml}$ of $10 \%$ trichloroacetic acid solution. Final supernatant was mixed with $0.5 \mathrm{ml}$ of anhydrous ethanol and then placed in a refrigerator at $4{ }^{\circ} \mathrm{C}$ for $24 \mathrm{~h}$. $0.4 \mathrm{ml}$ of the supernatant was centrifuged at 10,000 rpm for $15 \mathrm{~min}$. The resulting supernatant was added to $0.4 \mathrm{ml}$ of $0.15 \mathrm{~mol} / 1 \mathrm{H}_{2} \mathrm{SO}_{4}$ solution that placed in a boiling water bath for $15 \mathrm{~min}$ and afterwards allowed to return to room temperature. When cooled, $0.4 \mathrm{ml}$ of a $30 \% \mathrm{KOH}$ solution was slowly added while stirring, and the solution was returned to the boiling water bath for 15 min before the trehalose determination.
Table 1 Oviposition to eclosion durations of the nonoverwintering generation of Aphelinus mali for two genetic clades in China

\begin{tabular}{|c|c|c|c|c|c|}
\hline \multirow{2}{*}{\multicolumn{2}{|c|}{$\begin{array}{l}\text { Oviposition } \\
\text { to eclosion }\end{array}$}} & \multicolumn{2}{|l|}{ Shandong clade } & \multicolumn{2}{|l|}{ Liaoning clade } \\
\hline & & \multirow{2}{*}{$\begin{array}{l}\text { Duration }(D) \\
15.83 \pm 1.73 a\end{array}$} & \multirow{2}{*}{$\begin{array}{l}\text { Velocity }(V) \\
0.0632\end{array}$} & \multirow{2}{*}{$\begin{array}{l}\text { Duration }(D) \\
15.26 \pm 0.43 a\end{array}$} & \multirow{2}{*}{$\begin{array}{l}\text { Velocity }(\mathrm{V}) \\
0.0655\end{array}$} \\
\hline $18^{\circ} \mathrm{C}$ & q & & & & \\
\hline & $\hat{0}$ & $14.83 \pm 1.52 \mathrm{ab}$ & 0.0674 & $15.22 \pm 0.40 a$ & 0.0657 \\
\hline \multirow[t]{2}{*}{$20^{\circ} \mathrm{C}$} & 우 & $12.75 \pm 0.79 b$ & 0.0784 & $11.58 \pm 0.23 b$ & 0.0864 \\
\hline & $\hat{\sigma}$ & $12.94 \pm 0.66 b$ & 0.0773 & $11.94 \pm 0.06 b$ & 0.0838 \\
\hline \multirow[t]{2}{*}{$23^{\circ} \mathrm{C}$} & 우 & $9.69 \pm 0.61 c$ & 0.1033 & $9.67 \pm 0.69 c$ & 0.1034 \\
\hline & $\hat{\sigma}$ & $9.25 \pm 0.83 c d$ & 0.1206 & $6.83 \pm 0.60 \mathrm{de}$ & 0.1464 \\
\hline \multirow[t]{2}{*}{$25^{\circ} \mathrm{C}$} & q & $8.43 \pm 0.85 \mathrm{~cd}$ & 0.1186 & $7.84 \pm 0.09 d$ & 0.1275 \\
\hline & $\hat{0}$ & $8.29 \pm 0.85 \mathrm{cde}$ & 0.1206 & $7.33 \pm 0.33 d$ & 0.1364 \\
\hline \multirow[t]{2}{*}{$28^{\circ} \mathrm{C}$} & q & $6.50 \pm 1.51 \mathrm{e}$ & 0.1538 & $5.80 \pm 0.79 e$ & 0.1724 \\
\hline & $\hat{0}$ & $7.17 \pm 1.44 \mathrm{de}$ & 0.1395 & $7.06 \pm 0.53 \mathrm{de}$ & 0.1416 \\
\hline
\end{tabular}

Values in the table are mean $\pm S D$; different lowercase letters indicate significant differences in the same column

Thirty microliters of the liquid, with $300 \mu \mathrm{L}$ of anthrone, was placed in a boiling water bath for $15 \mathrm{~min}$ and then held in the dark for 20 30 min. The reflectance of the sample at $620 \mathrm{~nm}$ was then used to determine the level of trehalose by comparison to a known standard.

To determine the level of glycogen, the remaining precipitate was mixed with $0.5 \mathrm{ml}$ of distilled water, and when the precipitate was fully dissolved, it was used to measure glycogen levels (using the same method as above for trehalose). After the treatment with $300 \mu \mathrm{L}$ of anthrone, the reflectance of the sample at $620 \mathrm{~nm}$ was used to determine the level of glycogen by comparison to a known standard. These processes were repeated for five samples (each from the same time and place) for each parasitoid clade.

Table 2 Longevity of adults of the non-overwintering generation of Aphelinus mali for two genetic clades in China

\begin{tabular}{|c|c|c|c|c|c|}
\hline \multirow{2}{*}{\multicolumn{2}{|c|}{$\begin{array}{l}\text { Temperatures } \\
\left({ }^{\circ} \mathrm{C}\right)\end{array}$}} & \multicolumn{2}{|l|}{ Shandong clade } & \multicolumn{2}{|l|}{ Liaoning clade } \\
\hline & & \multirow{2}{*}{$\begin{array}{l}\text { Duration } \\
(D) \\
25.00 \pm 2.34 a\end{array}$} & \multirow{2}{*}{$\begin{array}{l}\text { Velocity } \\
\text { (V) } \\
0.0400\end{array}$} & \multirow{2}{*}{$\begin{array}{l}\text { Duration } \\
(D) \\
22.30 \pm 1.52 b\end{array}$} & \multirow{2}{*}{$\begin{array}{l}\text { Velocity } \\
(\mathrm{V}) \\
0.0448\end{array}$} \\
\hline 18 & q & & & & \\
\hline & $\hat{\sigma}$ & $23.00 \pm 5.29 a$ & 0.0435 & $19.72 \pm 1.67 \mathrm{bcd}$ & 0.0507 \\
\hline \multirow[t]{2}{*}{20} & q & $16.94 \pm 3.49 b$ & 0.0590 & $34.47 \pm 1.32 \mathrm{a}$ & 0.0290 \\
\hline & $\hat{\sigma}$ & $15.06 \pm 3.69 b c$ & 0.0664 & $31.94 \pm 0.97 a$ & 0.0313 \\
\hline \multirow[t]{2}{*}{23} & q & $15.63 \pm 3.00 b c$ & 0.0639 & $21.03 \pm 1.29 b c$ & 0.0475 \\
\hline & $\hat{\sigma}$ & $13.94 \pm 3.56 \mathrm{bcd}$ & 0.0717 & $17.41 \pm 1.65 \mathrm{cde}$ & 0.0574 \\
\hline \multirow[t]{2}{*}{25} & q & $13.64 \pm 7.26 \mathrm{cde}$ & 0.0733 & $14.84 \pm 1.42 \mathrm{ef}$ & 0.0674 \\
\hline & $\lesssim$ & $10.93 \pm 3.24$ def & 0.0915 & $10.94 \pm 0.78 f$ & 0.0914 \\
\hline \multirow[t]{2}{*}{28} & q & $10.10 \pm 7.38 \mathrm{ef}$ & 0.0990 & $16.39 \pm 1.54 \mathrm{de}$ & 0.0610 \\
\hline & $\hat{\delta}$ & $8.33 \pm 3.14 f$ & 0.1200 & $13.89 \pm 1.06 \mathrm{ef}$ & 0.0719 \\
\hline
\end{tabular}

Values in the table are mean $\pm S D$; different lowercase letters indicate significant differences in the same column 
Table 3 The lower developmental thresholds and total day-degree of non-overwintering generation of Aphelinus mali for two genetic clades in China

\begin{tabular}{|c|c|c|c|c|}
\hline \multirow{2}{*}{$\begin{array}{l}\text { Parasitoid clade } \\
\text { tested }\end{array}$} & \multicolumn{2}{|c|}{ Lower developmental threshold $\left({ }^{\circ} \mathrm{C}\right)$} & \multicolumn{2}{|c|}{ Total DD (day-degree) per life stage (oviposition to adult eclosion) } \\
\hline & Shandong clade & Liaoning clade & Shandong clade & Liaoning clade \\
\hline q & $9.32 \pm 1.62 \mathrm{a}$ & $12.96 \pm 1.56 b$ & $134.61 \pm 20.77 a$ & $88.42 \pm 16.65 b$ \\
\hline$\sigma^{\pi}$ & $10.61 \pm 1.58 \mathrm{a}$ & $13.33 \pm 0.79 b$ & $116.12 \pm 16.60 a$ & $82.02 \pm 7.36 b$ \\
\hline$q+\delta$ & $9.82 \pm 1.44$ & $10.72 \pm 0.24$ & $126.45 \pm 16.81$ & $107.99 \pm 3.44$ \\
\hline
\end{tabular}

Values in the table are mean \pm SD

\section{Protein content of overwintering larvae}

Thirty overwintering $A$. mali larvae were grouped and placed in a $1.5-\mathrm{ml}$ centrifuge tube to which $0.1 \mathrm{ml}$ of $0.04 \mathrm{~mol} / \mathrm{l}$ phosphate buffer $(\mathrm{pH}=7.0)$ was added. The samples were ground to homogenize the larvae and washed with $1.1 \mathrm{ml}$ of $0.04 \mathrm{~mol} / \mathrm{l}$ of phosphate buffer solution $(\mathrm{pH}=7.0)$. The homogenized sample was then fully extracted with $0.04 \mathrm{~mol} / \mathrm{l}$ phosphate buffer at $20 \sim 25{ }^{\circ} \mathrm{C}$ for $4 \mathrm{~h}$, and the solution was centrifuged at $6000 \mathrm{rpm}$ for $10 \mathrm{~min}$. A sample of $20 \mu \mathrm{L}$ of the resulting supernatant was collected and added to $80 \mu \mathrm{L}$ of $0.04 \mathrm{~mol} / \mathrm{l}$ phosphate buffer $(\mathrm{pH}=7.0)$ and $200 \mu \mathrm{L}$ of Coomassie brilliant blue (Shanghai Kayon Biological Technology Co., Ltd.). The sample was mixed by shaking and allowed to stand for 2 min before colorimetric analysis at $595 \mathrm{~nm}$ to measure the absorbance value, from which the free protein content was calculated by reference to a standard. This was done five times (from one sample date and place) for each parasitoid clade.

\section{Statistical analyses}

The average data of development at respective temperature conditions were calculated as the mean \pm standard deviation (SD) by SPSS 20.0. Significant differences in duration times were tested using one-way analysis of variance (ANOVA) corrected by SPSS 20.0. Independent sample $t$ tests were used to analyze the developmental duration of each clade by SPSS 20.0.

\section{Results and discussion}

Effective accumulated temperature and developmental threshold temperature

\section{Developmental duration}

Under the same temperature regime, there was no significant difference in development duration (egg to adult emergence) between males and females of the same clade of $A$. mali. Development duration significantly decreased with increasing temperature in each clade of A. mali (Table 1).

For females, development duration (from oviposition to adult emergence) of the Shandong clade was significantly longer than that of the Liaoning clade $(F=0.390$, $\mathrm{df}=4, P=0.048)$ at $20^{\circ} \mathrm{C}$ (Table 1$)$.

\section{Adult longevity}

Under the same temperature regime, female adults survived longer than males of the same clade, but this difference was not significant. Significant differences were found for longevity at different temperatures within the same clade (Table 2). Adult longevity decreased significantly (from $25.00 \pm 2.34$ to $10.10 \pm 7.38$ for female, $23.00 \pm 5.29$ to $8.33 \pm 3.14$ for male) with increasing temperature 18 to $28{ }^{\circ} \mathrm{C}$ in the Shandong clade, while the longest duration in the Liaoning clade was at $20{ }^{\circ} \mathrm{C}$ $(34.47 \pm 1.32$ for female, $31.94 \pm 0.97$ for male) and the shortest was at $25{ }^{\circ} \mathrm{C}(14.84 \pm 1.42$ for female, $10.94 \pm 0.78$ for male).

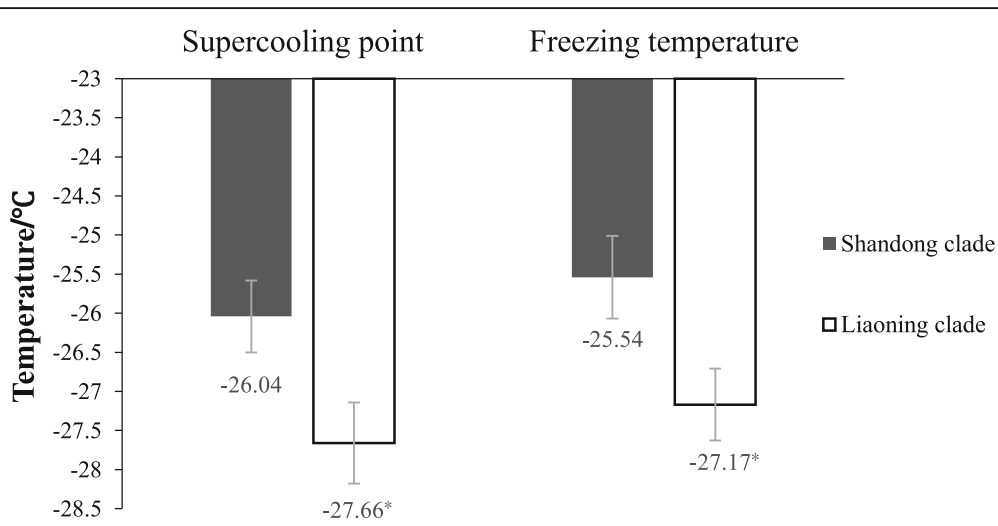

Fig. 1 Supercooling and freezing points of overwintering Aphelinus mali larvae for two genetic clades found in China. Asterisk indicates a significant difference at the 0.05 level 


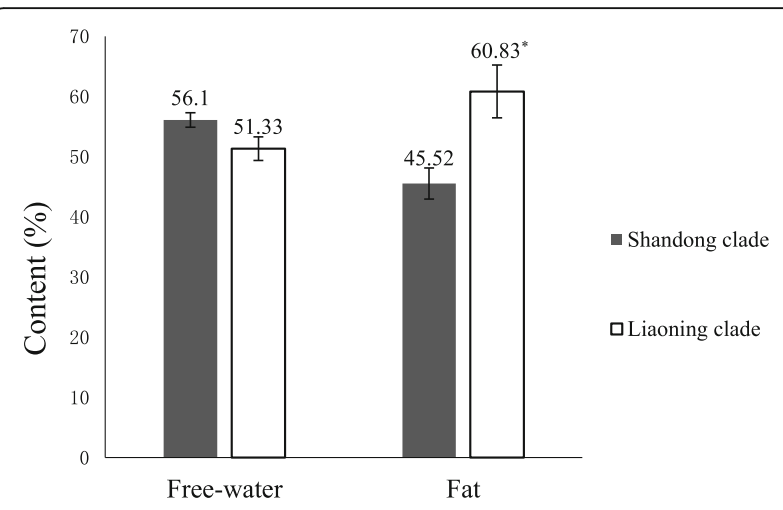

Fig. 2 Free-water and fat content of Aphelinus mali for two genetic clades found in China. Asterisk indicates a significant difference at the 0.05 level

Longevity of adult females was significantly greater for the Liaoning clade than for the Shandong clade at $20{ }^{\circ} \mathrm{C}$ $(F=0.394, \mathrm{df}=4, P=0.000)$ and $23{ }^{\circ} \mathrm{C}(F=1.302, \mathrm{df}=4$, $P=0.021)$. There were no significant differences in female longevity between the clades at the other temperatures (Table 2).

For males, adult longevity was significantly longer for the Liaoning clade than for the Shandong clade at $20{ }^{\circ} \mathrm{C}$ $(F=1.811, \mathrm{df}=4, P=0.000)$ and $28{ }^{\circ} \mathrm{C}(F=0.080, \mathrm{df}=4$, $P=0.028$ ), but not significantly different for the other temperatures (Table 2).

\section{Lower developmental thresholds and total day-degree for stage completion}

Results represented in Table 3 showed that the lower developmental thresholds of both males and females of the Shandong clade were lower $(F=3.350, \mathrm{df}=3, P=0.026$; $F=0.150, \mathrm{df}=3, P=0.012)$ than those of the Liaoning clade.

Meanwhile, the total day-degree for stage completion of the Shandong clade was greater than that of the Liaoning clade $(F=5.907, \mathrm{df}=3, P=0.028)$ (Table 3$)$.
In this study, we found that the larval and pupal stages of Shandong clade females $\left(9.32 \pm 1.62{ }^{\circ} \mathrm{C}\right)$ and males $\left(10.61 \pm 1.58{ }^{\circ} \mathrm{C}\right)$ both had lower developmental threshold temperatures than that of the Liaoning clade $\left(12.96 \pm 1.56{ }^{\circ} \mathrm{C}, 13.33 \pm 0.79{ }^{\circ} \mathrm{C}\right.$, respectively). The total day-degree for stage completion of Shandong clade females (134.61 \pm 20.77 DD) and males (116.12 $\pm 16.60 \mathrm{DD})$ were both higher than that of the Liaoning clade $(88.42 \pm 16.65 \mathrm{DD}, 82.02 \pm 7.36 \mathrm{DD})$ from oviposition to adult eclosion. In Mols and Boers' study, the low-temperature threshold of the Nova Scotian (Canada) strain $\left(8.6^{\circ} \mathrm{C}\right)$ was lower than that of the Dutch (Nederland) strain $\left(9.4^{\circ} \mathrm{C}\right)$ (Mols and Boers 2001), allowing it to appear earlier in spring, thus providing better control. The developmental threshold temperature of the Shandong clade was lower than that of the Liaoning clade in the present study, suggesting that $A$. mali of Shandong clade can occur earlier in spring and may therefore provide better control of woolly apple aphid at a lower population level of the pest.

\section{Supercooling points and freezing temperatures of overwintering larvae of the two clades}

The supercooling $\left(-26.04{ }^{\circ} \mathrm{C}\right)$ and freezing $\left(-25.54{ }^{\circ} \mathrm{C}\right)$ points of the Shandong clade were significantly higher than corresponding values for the Liaoning clade $\left(-27.66{ }^{\circ} \mathrm{C}\right.$ and $-27.17{ }^{\circ} \mathrm{C}$, respectively) $(F=0.167, \mathrm{df}=58, P=0.024$; $F=0.088, \mathrm{df}=58, P=0.023$, respectively) (Fig. 1).

Freeze tolerance and freeze avoidance are two alternative strategies for survival at sub-zero temperatures, with freeze avoidance being thought to predominate in moderately cold and predictable thermal environments (Sean et al. 2015). Freeze tolerance, on the other hand, is the ability of certain insects to enhance their cold resistance by regulating the body's supercooling state (Zhang and Ma 2013) so that at temperatures below freezing, the insect's body fluid remains liquid. The supercooling points of the Shandong clade of overwintering larvae and freezing point were both

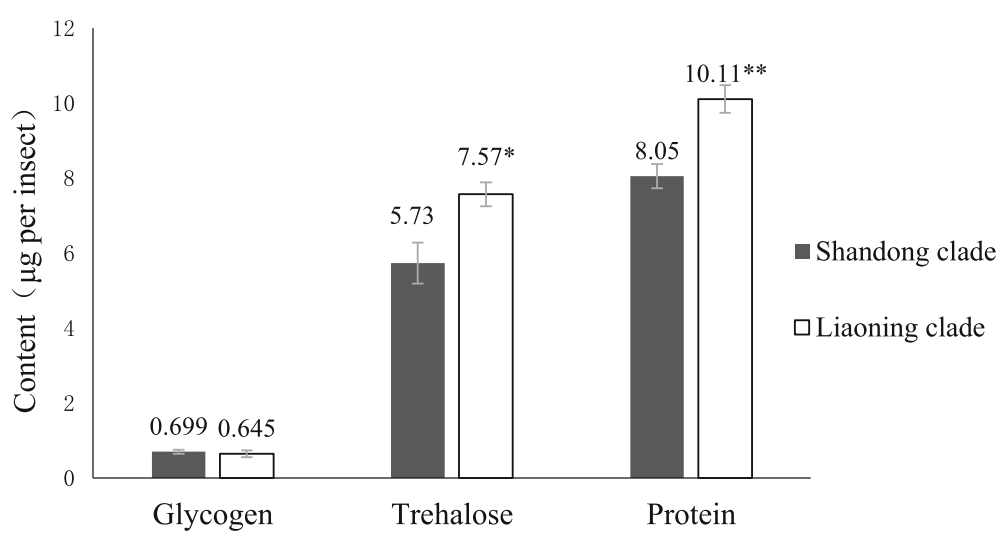

Fig. 3 Glycogen, trehalose, and protein levels of Aphelinus mali for two genetic clades found in China 
higher than that of the Liaoning clade, suggesting that the cold resistance of the Liaoning clade is stronger than that of Shandong clade.

\section{Levels of cryoprotectants in overwintering parasitoid larvae of each clade}

While there were differences in sample means for the free-water content of the two clades, they were not significant $(F=0.625, \mathrm{df}=8, P=0.072)$. In contrast, the fat content of the Shandong clade $(45.5 \%)$ was significantly different from that of the Liaoning clade (60.8\%) $(F=2.836, \mathrm{df}=8, P=0.017)$ (Fig. 2).

There were no significant differences in glycogen content between the two clades $(F=0.216, \mathrm{df}=8, P=0.613)$. Trehalose levels, however, were significantly lower in the Shandong clade $(5.73 \mathrm{~g} / \mathrm{larvae}, 25.37 \mathrm{~g} / \mathrm{mg})$ than in the Liaoning clade $(7.57 \mathrm{~g} /$ larvae, $36.12 \mathrm{~g} / \mathrm{mg})(P=0.020$, $P=0.008$, respectively). Protein content was also significantly lower in the Shandong clade $(8.05 \mathrm{~g} /$ larvae, $35.68 \mathrm{~g} / \mathrm{mg})$ than in the Liaoning clade $(10.11 \mathrm{~g} /$ larvae, $48.20 \mathrm{~g} / \mathrm{mg})(P=0.003, P=0.001$, respectively) (Fig. 3).

In cold environments, the free-water content in insect bodies is greatly reduced, leading to an increase in the concentration of body solutes and thus reducing its freezing point (Feng et al. 2014). Cold-resistant substances of insects include two types, small molecules and antifreezing proteins (Chen et al. 2010). Cold-resistant small molecules include glycerol, sorbitol, mannitol, five carbon polyol (probably Arabia sugar alcohol or nucleic acid alcohol), trehalose, glucose, fructose, and some amino and fatty acids (Chen et al. 2010).

\section{Conclusions}

Recent study of Zhang and Ma (2013) reported that insects in low-latitude areas had higher cooling points than insects in high-latitude areas. By comparing the supercooling point and the levels in the insect's body of coldresistant materials for the two clades of $A$. mali, we found that the cold resistance of the Liaoning clade was higher than that of Shandong clade, possibly because of increasing latitude or genetic differentiation. Future studies should compare the cold resistance ability of the two clades from populations at the same latitude. A better understanding of the life table parameters of this parasitoid, as well as the genetic variation within populations, will allow for more accurate use of this insect to control WAA in China.

\section{Acknowledgements}

We would like to thank Chai Xiaojing and Yan Hao of the College of Agronomy and Plant Protection, Qingdao Agricultural University, China, for their help. This work was supported by the National Natural Science Foundation (31371994), National Natural Science Foundation (31772232), the National Key Research and Development Plan (2016YFC1201200), Major scientific and technological innovation project of Shandong Province (2017CXGC0214), the National Key
Basic Research Development Plan Project (2013CB127600), and the Taishan Mountain Scholar Constructive Engineering Foundation of Shandong, China.

Authors' contributions

MS carried out the whole experiments at room condition and drafted the manuscript. XT corrected the English manuscript. QY collected A. mali from Qingdao and Qinhuangdao. FW participated in the design of the study $\mathrm{HZ}$ conceived of the study and participated in its design and coordination. All authors read and approved the final manuscript.

\section{Competing interests}

The authors declare that they have no competing interests.

\section{Publisher's Note}

Springer Nature remains neutral with regard to jurisdictional claims in published maps and institutional affiliations.

\section{Author details}

${ }^{1}$ College of Plant Health and Medicine, Key Lab of Integrated Crop Pest Management of Shandong Province, Qingdao Agricultural University, Qingdao 266109, China. ${ }^{2}$ General Station of Plant Protection of Shandong Province, Jinan 250100, China. ${ }^{3}$ State Key Laboratory for Biology of Plant Diseases and Insect Pests, Institute of Plant Protection, Chinese Academy of Agricultural Sciences, Beijing 100081, China.

Received: 7 July 2017 Accepted: 6 December 2017

Published online: 30 January 2018

\section{References}

Chen H, Liang GM, Zou LY, Guo F, Wu KM, Guo YY (2010) Research progresses in the cold hardiness of insects. Plant Prot 36(2):18-24

Chu MP, Liu ZQ, Wu Y, Hu J, Gong WR (2008) Occurrence and comprehensive prevention and control measures in Jiangsu province of woolly apple aphid. Jiangsu Agricultural Science 6:128-129

Feng YQ, Wang JL, Zong SX (2014) Review of insects overwintering stages and cold-resistance strategies. Chin Agric Sci Bull 30(9):22-25

Folch J, Lees M, Stanley GHS (1957) A simple method for the isolation and purification of total lipids from animal tissues. J Biol Chem 226(1):497-507

Gontijo LM, Cockfield SD, Beers EH (2012) Natural enemies of woolly apple aphid (Hemiptera: Aphididae) in Washington state. Environ Entomol 41(6):1364-1371

Jaume L, Simó A, Ferran G, José S, Georgina A (2015) Woolly apple aphid Eriosoma lanigerum Hausmann ecology and its relationship with climatic variables and natural enemies in Mediterranean areas. B Entomol Res 105(1):60-69

Long CD, Wang YP, Tang PZ (1960) Biological characteristics and its utilization of woolly apple aphid parasitoid (Aphelinus mali Haldeman). Acta Entomol Sin 10(1):1-37

Lu ZY, Liu WX, Ran HF, Qu ZG, Li JC (2013) Investigation of the population dynamics of Eriosoma lanigerum and its parasitoids Aphelinus mali in apple orchards in central Hebei. J Agric Univ Hebei 36(3):87-91

Ma LQ (2009) Effective accumulated temperature and developmental threshold temperature for Semanotus bifasciatus (Motschulsky) in Beijing. Forestry Studies in China

Mols PJM, Boers JM (2001) Comparison of a Canadian and a Dutch strain of the parasitoid Aphelinus mali (Hald.) (Hym., Aphelinidae) for control of woolly apple aphid Eriosoma lanigerum (Haussmann) (Hom., Aphididae) in the Netherlands: a simulation approach. J Appl Entomol 125(5):255-262

Sean DS, Rachel AS, James CB, Glenda AV (2015) Conserved and narrow temperature limits in alpine insects: thermal tolerance and supercooling points of the ice-crawlers, Grylloblatta (Insecta: Grylloblattodea: Grylloblattidae). J Insect Physiol 78(2):55-61

Wang $X Y$, Jiang $C T, X u G Q$ (2011) Potential distribution of an invasive pest Eriosoma lanigerum in China. Chin J Appl Entomol 48(2):379-391

Wu Q, Wan FH, Li ZH (2009) Investigations on invasion situation and control strategies of Eriosoma lanigerum in China. Plant Prot 35(5):100-104

Zhang Q, Luo WC (2002) Occurrence characteristics of Eriosoma lanigerum and its control methods. Entomological Knowledge 39(5):340-342

Zhang R, Ma J (2013) Insect supercooling point and its influence factors. Tianjing Agricultural Science 19(11):76-84

Zhang RM, Zhou HX, Guo D, Tao YL, Wan FH, Wu Q, Chu D (2014) Two putative bridgehead populations of Aphelinus mali (Hymenoptera: Aphelinidae) 
introduced in China as revealed by mitochondrial DNA marker. Fla Entomol 97(2):401-405

Zhou HX, Guo JY, Wan FH, Yu Y (2010) Aphelinus mali to woolly apple aphid natural control and its protection and utilization. Acta Phytophylacica Sinica 02:153-158

Zhou HX, Zhang RM, Guo D, Tao YL, Wan FH, Wu Q, Chu D (2014) Analysis of genetic diversity and structure of two clades of Aphelinus mali

(Hymenoptera: Aphelinidae) in China. Fla Entomol 97(2):699-706

\section{Submit your manuscript to a SpringerOpen ${ }^{\bullet}$} journal and benefit from:

- Convenient online submission

- Rigorous peer review

- Open access: articles freely available online

- High visibility within the field

- Retaining the copyright to your article

Submit your next manuscript at $\gg$ springeropen.com 